\title{
Nanoimprint Resist Stress Analysis under Low Temperature by Finite Element Analysis
}

\author{
Hongwen Sun ${ }^{1, ~ a}$, Xiaochao $\mathrm{Ma}^{1, \mathrm{~b}}$ and Chenhui $\mathrm{Hu}^{1, \mathrm{c}}$ \\ ${ }^{1}$ College of Internet of Things Engineering, Hohai University. 200 JinLing Road North, Changzhou, \\ China 213022 \\ ahhucshw@163.com, ${ }^{b}$ maxciod2c@163.com, cjdcholi80@163.com
}

\begin{abstract}
Keywords: thermal nanoimprint lithography, nanoimprint lithography, low temperature nanoimprint lithography, resist, stress, finite element analysis.

Abstract. Traditional thermal nanoimprint lithography (TNIL) needs high temperature. This limits its application in the biological and medical area where substrate cannot sustain high temperature. Low temperature nanoimprint lithography (LTNIL) allows imprint conducted under temperature a little higher than transition temperature of the resist. However, in order to replicate with high fidelity, the process parameters should be optimized. This contribution employed finite element analysis to research the stress of nanoimprint resist under low temperature from three angles: imprint temperature, pressure on stamp and imprint time. The contact part between the stamp and resist has bigger stress than other areas. The bottom of the resist has minimum stress. With proper imprint temperature and time, the resist can fully fill the cavity of the stamp and the stress of the resist does not change anymore. The stress of the resist increases with the pressure on the stamp.
\end{abstract}

\section{Introduction}

Nanoimprint lithography (NIL), as an important nanofabrication technique, has the benefits of high resolution, high uniformity and low cost [1]. It can fabricate nano features as small as $5 \mathrm{~nm}$. Therefore, it has been as a possible candidate of next generation lithography (NGL) in the report of ITRS (The International Technology Roadmap for Semiconductors). Except microelectronics, NIL can also be widely used in the areas of optics, biological and medical [2]. However, traditional thermal nanoimprint lithography (TNIL) needs high temperature, which needs long process time and increase thermal stress [3]. Therefore, it is necessary to conduct research on low temperature nanoimprint lithography (LTNIL) [4,5]. In LTNIL process, the resist is heated to a temperature just beyond the polymer's glass transition temperature $\left(\mathrm{T}_{\mathrm{g}}\right)$. LTNIL can provide samples which cannot sustain high temperature.

Scheer et al. examined the polymer time constants for low temperature NIL [6]. Chen et al. imprinted SU-8 and NEB-22 at low temperature [7]. Lu et al. used room temperature imprint to pattern multilayer films poly(acrylic acid)/poly(allylamine hydrochloride) [8]. Employing Finite Element Method (FEM) to analyze the LTNIL process is a good approach to save time and cost. This method can help to understand the relationship between the process parameters and the inner properties. This contribution employed finite element analysis (FEA) to research the stress of nanoimprint resist in the condition of low temperature NIL.

\section{Modeling}

To save time, a simplified model was set up, in which the stamp had one cavity. The typical model is shown in Figure 1. The width of the stamp cavity L3 is $200 \mathrm{~nm}$ and the depth of the cavity is $100 \mathrm{~nm}$. The width of the elevated part of the stamp L6 is 40nm The initial thickness of the resist L11 is 150nm. The length of the resist and stamp L10 is 280nm. The element type of the stamp is Plane42 and element type Hyper56 for the resist. The reference temperature of NIL is 300K. 


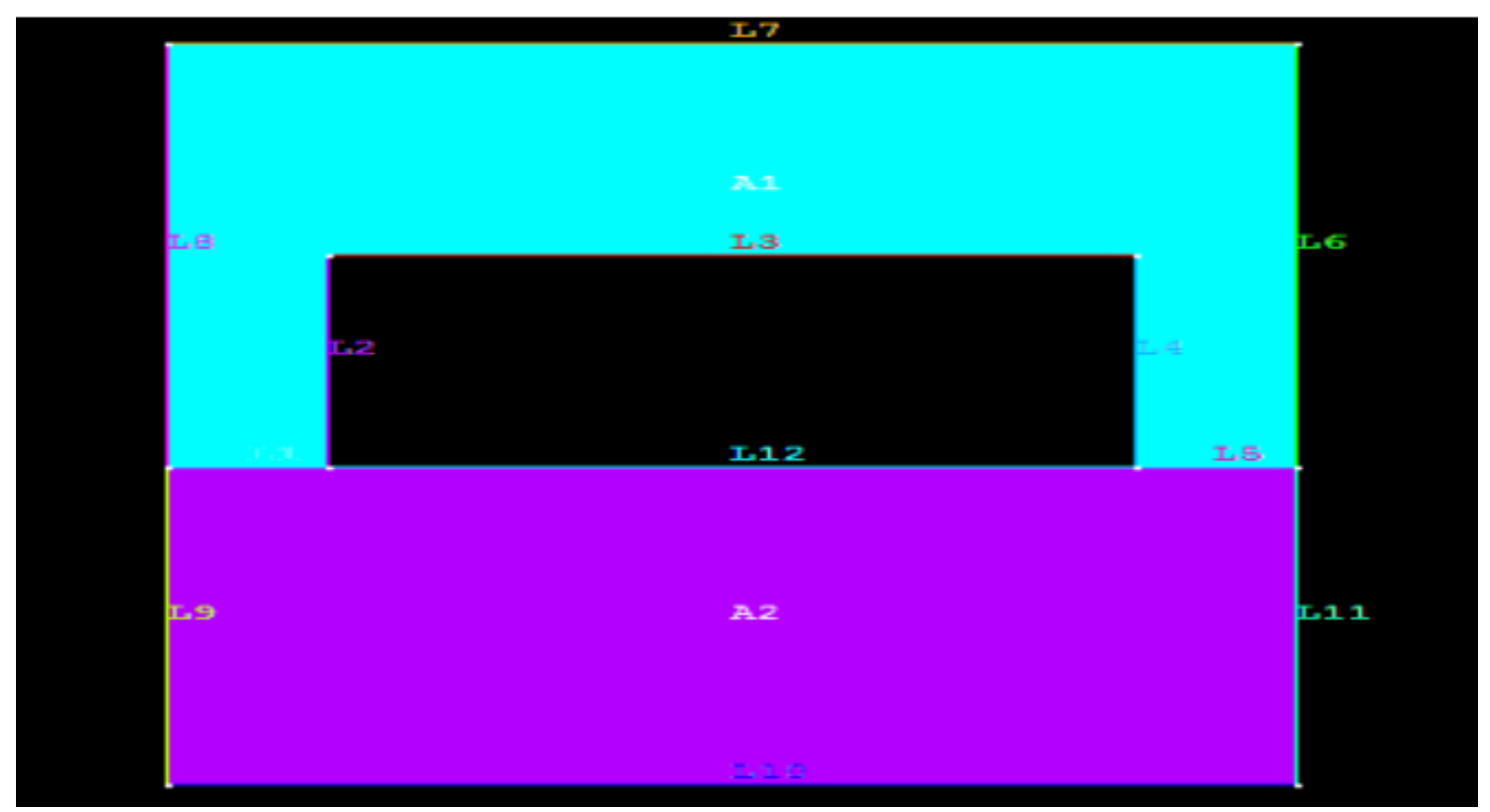

Fig. 1 Typical model having one cavity (Blue part stands for stamp and Purple stands for resist)

The stamp material employed was Silicon (Si). The traditional imprint polymer poly(methyl methacrylate) (PMMA) was taken as the resist. The material parameters of them are given in Table 1.

Table 1 Material parameters of Si and PMMA

\begin{tabular}{cccccc}
\hline material & $\begin{array}{c}\text { elastic } \\
\text { modulus [GPa] }\end{array}$ & $\begin{array}{c}\text { poisson's } \\
\text { ratio }\end{array}$ & $\begin{array}{c}\text { density } \\
{\left[\mathrm{kg} / \mathrm{m}^{3}\right]}\end{array}$ & $\begin{array}{c}\text { thermal conductivity } \\
{[\mathrm{W} / \mathrm{m} \cdot \mathrm{K}]}\end{array}$ & $\begin{array}{c}\text { specific heat } \\
\text { capacity }[\mathrm{J} / \mathrm{kg} \cdot \mathrm{K}]\end{array}$ \\
\hline $\mathrm{Si}$ & 190 & 0.300 & 2330 & 149 & 700 \\
\hline PMMA & 2.35 & 0.499 & 1200 & 0.21 & 1464 \\
\hline
\end{tabular}

\section{Results and Discussion}

\section{Temperature's impact on resist stress}

The pressure applied on the stamp is $1 \times 10^{10} \mathrm{~Pa}$. In this section, four situation with temperature $420 \mathrm{~K}, 400 \mathrm{~K}, 380 \mathrm{~K}$ and $370 \mathrm{~K}$ was simulated while other parameters kept the same. Figure 2 shows the displacement contour of the resist at $420 \mathrm{~K}$. From this figure, it can be noticed that the resist fully fill the cavity. The resist used to fill the cavity is mainly from the parts under the elevated part of the stamp.

From our simulation, we found that the stress increases sharply with the imprint time at the initial period of imprint. After the resist fully fills the cavity, the resist's stress does not change greatly and become stable. Figure 3 gives the final Von Mises stress contour of the resist at $420 \mathrm{~K}$ with pressure $1 \times 10^{10} \mathrm{~Pa}$. The stress in most parts of the resist is almost the same, except the contact part with the stamp. The contact part shows bigger stress. At other temperatures, the resist stress distribution shows the same regular. The maximum stress and minimum stress is nearly the same for $380 \mathrm{~K}, 400 \mathrm{~K}$ and $420 \mathrm{~K}$. However at $370 \mathrm{~K}$, both maximum and minimum stress reduced. It demonstrates that at temperature higher than $T_{g}$ of the resist, the final stress has little relationship with the imprint temperature.

\section{Pressure's impact on resist stress}

At this section, the imprint temperature was set up at a low temperature 380K. Different imprint pressure situation was simulated. At $1 \times 10^{5} \mathrm{~Pa}$, the resist does not fill the cavity of the stamp. At $1 \times 10^{8}$ $\mathrm{Pa}$, the resist only partly fill the cavity. We increased the pressure to $1 \times 10^{10} \mathrm{~Pa}$, and found the resist can fully fill the cavity. The stress changes greatly in the contact area between the stamp and the resist. The contact part also has the maximum stress, while the bottom area of the resist has the minimum 
stress. The maximum and minimum Von Mises stress is shown in Table 2. With applied pressure on the stamp increases, the stress of the resist increases accordingly.

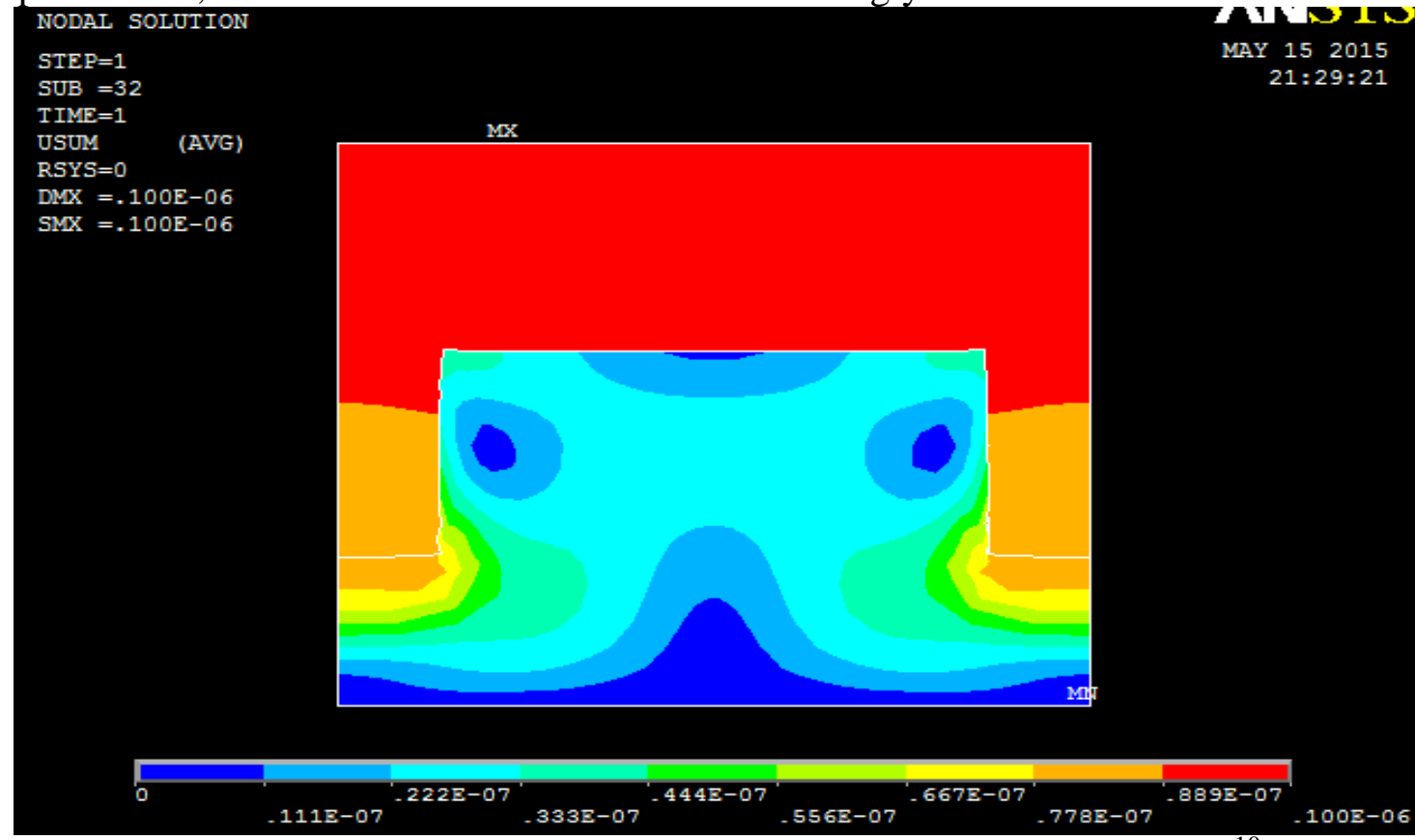

Fig. 2 Displacement contour of the resist at $420 \mathrm{~K}$ with pressure $1 \times 10^{10} \mathrm{~Pa}$ NODAL SOLUTION

$\mathrm{STEP}=1$

SUB $=32$

TIME $=1$

SEQV (AVG)

$\mathrm{DMX}=.100 \mathrm{E}-06$

$\mathrm{SMN}=.506 \mathrm{E}+08$

$\operatorname{SMX}=.349 \mathrm{E}+11$

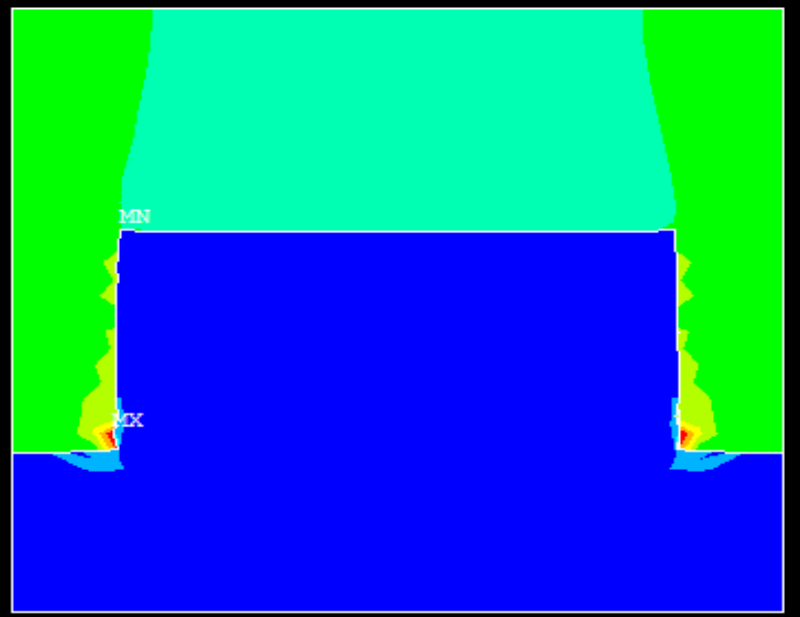

MAY $15 \quad 2015$ $21: 32: 37$

SMa $=.349 \mathrm{E}+11$

$5068+08$

$-779 \mathrm{~B}+10$

$1178+11-155 \mathrm{E}+11$

$194 \mathrm{~B}+11$

$233 \mathrm{~B}+11$

Fig. 3 Von Mises stress contour of the resist at $420 \mathrm{~K}$ with pressure $1 \times 10^{10} \mathrm{~Pa}$

Table 2 Maximum and minimum Von Mises stress at 380K with different pressure

\begin{tabular}{ccc}
\hline Pressure & Maximum stress & Minimum stress \\
\hline $1 \times 10^{5} \mathrm{~Pa}$ & $8.89 \times 10^{5} \mathrm{~Pa}$ & $5454 \mathrm{~Pa}$ \\
\hline $1 \times 10^{8} \mathrm{~Pa}$ & $1.19 \times 10^{9} \mathrm{~Pa}$ & $1.79 \times 10^{6} \mathrm{~Pa}$ \\
\hline $1 \times 10^{10} \mathrm{~Pa}$ & $2.56 \times 10^{10} \mathrm{~Pa}$ & $4.71 \times 10^{9} \mathrm{~Pa}$ \\
\hline
\end{tabular}

\section{Time's impact on resist stress}

In this section, the resist temperature is $380 \mathrm{~K}$ and applied pressure on the stamp is $1 \times 10^{10} \mathrm{~Pa}$. Through simulation by changing imprint time, it was found that the resist stress increase with time increase at first. Table 3 gives the maximum and minimum Von Mises stress at different time. It 
appears linear relationship between stress and time for both maximum stress and minimum stress. After 1s, the resist stress does not change with time.

Table 3 Maximum and minimum Von Mises stress at $380 \mathrm{~K}$ and $1 \times 10^{10} \mathrm{~Pa}$ at different imprint time

\begin{tabular}{ccc}
\hline Time & Maximum stress & Minimum stress \\
\hline $0.1 \mathrm{~s}$ & $3.49 \times 10^{11} \mathrm{~Pa}$ & $5.06 \times 10^{8} \mathrm{~Pa}$ \\
\hline $1.0 \mathrm{~s}$ & $3.49 \times 10^{12} \mathrm{~Pa}$ & $5.06 \times 10^{9} \mathrm{~Pa}$ \\
\hline
\end{tabular}

\section{Conclusion}

Low temperature nanoimprint lithography has the advantage of low stress, short thermal cycle, and bio compatible. Employing finite element analysis to investigate the inner property like stress can save researcher's time and reduce the use of expensive stamp and resist. Nanoimprint resist's stress was studied by FEA in this contribution from three angles, which are imprint temperature, pressure on stamp and imprint time. It was found that the stress in most parts of the resist is almost the same, except the contact part with the stamp, which has bigger stress. At temperature higher than $T_{g}$ of the resist, the final stress has little relationship with the imprint temperature. With applied pressure on the stamp increases, the stress of the resist increases. The resist stress increase with time at first. After imprint finishes, the resist stress does not change with time.

\section{Acknowledgements}

This work was financially supported by "the Fundamental Research Funds for the Central Universities” (2015B22514).

\section{References}

[1] S.Y. Chou, P. R. Krauss and P. J. Renstrom: Appl. Phys. Lett. Vol. 67 (1995), p. 3114

[2] M.J. Lima, V.M. Correlo and R.L. Reis: Materials Science and Engineering C Vol. 42 (2014), p.615

[3] C.M.S. Torres, K.Y.S. Zan, J. Seekamp, et al: Material Science and Engineering Vol. 23 (2003), p. 23

[4] N. Ikutame, K. Kawaguchi, H. Ikeda, et al: J. Appl. Phys. Vol. 114 (2013), p. 8

[5] J. Kettle, S. Whitelegg, A.M. Song, et al: Nanotechnology Vol. 21 (2010), p. 075301

[6] H.C. Scheer, N. Bogdanski, M. Wissen, et al: J. Vac. Sci. Technol. B Vol. 23 (2005), p. 2963

[7] H.L. Chen, S.Y. Chuang, H.C. Cheng, et al: Microelectron. Eng. Vol. 83 (2006), p. 893

[8] Y. Lu, J. Sun and J. Shen: Langmuir Vol. 24 (2008), p. 8050 